\title{
Information Power in Intelligent Transport Systems
}

P. Moos*, M. Svítek*, Z. Votruba*

Faculty of Transportation Sciences, Czech Technical University in PragueCzech Republic

*Corresponding authors : moos@fd.cvut.cz,svitek@fd.cvut.cz,votruba@fd.cvut.cz

ABSTRACT: The decision making process in the environment of an Intelligent transport system (ITS) with a high level of uncertainty is strongly dependent on the level of conceptual and contextual knowledge. The effectiveness of the decision making process of ITS relates to the available information power $(\mathrm{P})$ which is considered as a vector in the plane given by the orthogonal system of information flow $(\Phi)$ and information content (I). The paper introduces the information power as data, information and knowledge alliance. This approach enables us to measure the ITS effectiveness through information power and yields directly to optimal prognoses given by information power maximization, or, in other words, information resonance.

KEY WORDS: Information power, data, information, alliance, intelligent transport systems

\section{DATA, INFORMATION, AND KNOWLEDGE ALLIANCE}

Let us suppose that $\mathrm{O}_{i}$ is a set of rated quantities on an object. $\mathrm{P}_{\mathrm{i}}$ is a set of states (observers), $\Phi_{i}$ is a set of syntactic strings (data flow), and $I_{i}$ is a set of information images of state quantities. The Fregge functional concept of information image origin (Vlček, 2003) can be stated in the following graphic form:

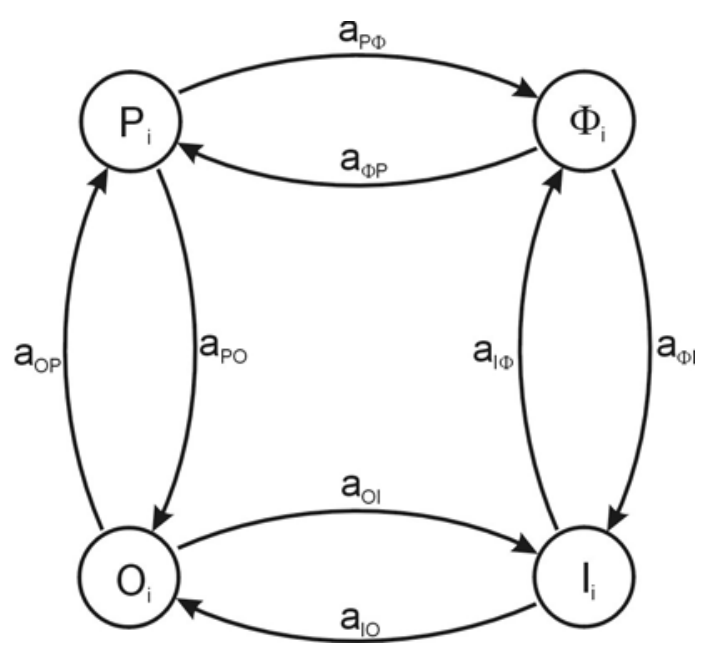

Figure 1: Fregge functional concept of information image origin and action

$$
\begin{array}{ll}
a_{O P} & - \text { identification } \\
a_{P O} & - \text { invasivity }
\end{array}
$$




$$
\begin{array}{ll}
a_{P \Phi} & - \text { projection in a set of symbols and syntactical strings } \\
a_{\Phi P} & - \text { uncertainty correction and identification } \\
a_{\Phi I} & - \text { interpretation, information origin } \\
a_{I \Phi} & - \text { language constructs reflection } \\
a_{I O} & - \text { relation of functions and structural regularity } \\
a_{O I} & - \text { integrity verification }
\end{array}
$$

If $\mathrm{P}\left\{\mathrm{O}_{\mathrm{i}} \quad\left(\mathrm{t}_{\mathrm{x}}\right)\right\}=\mathrm{O}_{\mathrm{i}}$ is a sequence of the object's states $\mathrm{O}_{\mathrm{i}}$, , then the image of the sequence $\left\{\begin{array}{llllllllll}\mathrm{O}_{\mathrm{i}} & \left(\mathrm{t}_{1}\right), & \mathrm{O}_{\mathrm{i}} & \left(\mathrm{t}_{2}\right) & \ldots & \mathrm{O}_{\mathrm{i}} & \left(\mathrm{t}_{\mathrm{x}}\right)\end{array}\right\}$ can be symbolically written as $\left\{\mathrm{I}_{\mathrm{i}}\left(\mathrm{t}_{1}\right), \mathrm{I}_{\mathrm{i}}\left(\mathrm{t}_{2}\right) \ldots \mathrm{I}_{\mathrm{i}}\left(\mathrm{t}_{\mathrm{x}}\right)\right\}$.

We can also write $\mathrm{P}\left\{\mathrm{I}_{\mathrm{i}}\left(\mathrm{t}_{\mathrm{x}}\right)\right\}=\mathrm{I}_{\mathrm{i}}$. The difference of state representations $\mathrm{dO}_{\mathrm{ix}}=\mathrm{O}_{\mathrm{i}}\left(\mathrm{t}_{\mathrm{x}}\right)-\mathrm{O}_{\mathrm{i}}$ $\left(\mathrm{t}_{\mathrm{x}-1}\right)$ shall be called an event. The sequence of events $\mathrm{U}\left\{\mathrm{dO}_{\mathrm{ix}}\right\}=\left\{\mathrm{dO}_{\mathrm{i} 1}, \mathrm{dO}_{\mathrm{i} 2} \ldots \mathrm{dO}_{\mathrm{ik}}\right\}$ represents a process recognized on the object. The sequence of events information images $\mathrm{U}_{\mathrm{I}}\left\{\mathrm{dI}_{\mathrm{ix}}\right\}=\left\{\mathrm{dI}_{\mathrm{i} 1}, \mathrm{dI}_{\mathrm{i} 2} \ldots \mathrm{dI}_{\mathrm{ik}}\right\}$ characterizes the process information image.

Let us permit that, for the object framework $\mathrm{O}\left\{\mathrm{O}_{1}, \mathrm{O}_{2} \ldots \mathrm{O}_{\mathrm{k}}\right\}$, there is an image assignment $I\left\{I_{1}, I_{2}, \ldots I_{k}\right\}$ and this assignment system shall be further called the syntactical information system. The sequence of events information images $\mathrm{U}_{\mathrm{I}}\left\{\mathrm{dI}_{\mathrm{ix}}\right\}$ creates process information systems. In more complex systems, there are always more objects and more processes in a mutual relation where the mutual share in the arrangement of the system and the share of process parts create an alliance among objects, an alliance among processes.

Syntactical frameworks are characterized by the following relationship:

$$
\underbrace{\left(\begin{array}{l}
O_{1}\left(t_{i}\right) \\
O_{2}\left(t_{i}\right) \\
O_{k}\left(t_{i}\right)
\end{array}\right) \rightarrow\left(A_{s}\right) \rightarrow\left(\begin{array}{c}
I_{1}\left(t_{i}\right) \\
I_{2}\left(t_{i}\right) \\
\\
I_{k}\left(t_{i}\right)
\end{array}\right)}
$$

Syntactical systems relation

While the relationship:

$$
\begin{gathered}
\left\{\mathrm{O}_{\mathrm{k}}\left(\mathrm{t}_{1}, \mathrm{t}_{2} \ldots \mathrm{t}_{\mathrm{x}}\right) \mathrm{O}_{\mathrm{e}}\left(\mathrm{t}_{1}, \mathrm{t}_{2} \ldots \mathrm{t}_{\mathrm{x}}\right) \ldots \mathrm{O}_{\mathrm{z}}\left(\mathrm{t}_{1}, \mathrm{t}_{2} \ldots \mathrm{t}_{\mathrm{x}}\right)\right\} \stackrel{A_{p}}{\longrightarrow} \\
\longrightarrow
\end{gathered}
$$

represents a set of processes - a process information system.

The state-of-the-art in information and communication technologies is based upon the convergence of telecommunication and medial data formats. Hence, the terms like the data systems "alliance" in different multiplex standards and sharing transmission, communication, and memory systems are used. It results from the initial model representation that even databases represent sets of non-interpreted data on an object's state. It means that a possibility of different interpretation sources origination can be awaited only within a single shared data set. 
The term information is usually pertinent to the process of uncertainty elimination or, optionally, to an increase in a system's ordering. Therefore, information can be expressed by the ordering change rate and the definition can be formulated as follows: Information is "interpreted data, entries, or signals leading to ordering changes in systems of the real world or consciousness".

Quantitative evaluation of information, information flows is impossible without the definition of an information measure and the definition expressing an information flow in a transmission channel. Nevertheless, we will consider a signal as a code carrier enabling expressing data in such a form to be able to transfer and preserve them. In transmission systems and data processing frameworks, we cannot do without the expression of a transmission capacity and without a data storage capacity. To be able to express this capacity we need to find relations by means of which we could express the information amount in a quantitative manner. The properties of a real object or an object in the real world can be described with the help of $n$ possible partial reports. Each of those reports consists of the alphabet $\underline{\mathrm{A}}\left(\mathrm{A}_{1}, \mathrm{~A}_{2} \ldots \mathrm{A}_{\mathrm{s}}\right)$ where $\mathrm{S}$ is the number of characters in the selected alphabet. If $n$ represents the number of elements in a character set then the number of possible reports expressed by the alphabet $\underline{\mathrm{A}}$ is given by the formula:

$$
N=S^{n}
$$

where $\mathrm{N}$ is the number of possible messages; $\mathrm{S}$ is the number of characters in the alphabet $\underline{\mathrm{A}}\left(\mathrm{A}_{1}, \mathrm{~A}_{2} \ldots \mathrm{A}_{\mathrm{s}}\right)$; and $n$ is the number of elements in the character set.

It is evident that one message can be expressed by different alphabets consisting of a various number of characters. Therefore, the same number of messages may be transferred by different numbers of elements in a character set using different alphabets. So, in terms of transfer, a message of the same contents may be transferred by a greater or smaller number of characters and may require a larger or lesser channel transfer capacity.

The Hartley tolerance measure of information (Moos at al.2008) is defined:

$$
I=K \ln N=K n \ln S
$$

With the help of entropy, information contents in messages are characterized in which symbols are not distributed in a uniform pattern but occur with a $p$ probability; the entropy mean value per one symbol may be stated as follows (this formula was derived by C. E. Shanon in 1948):

$$
H=-\sum_{i=1}^{S} K p_{i} \ln p_{i}
$$

In the case of a binary symbol system $(0 ; 1)$, the $\mathrm{K}$ constant, which is also used in equations (4) and (5), can be expressed under assumption of the same probabilities of the symbols 0,1 occurrence:

$$
K=\frac{1}{\ln 2}
$$


Knowledge represents an ability of assignment, classification, and filtration of data, entries, and information images of objects' probable states and their state transitions and interpretation of causal strings and sensibilities on sets of uncertainties, information images of states and transitions in system links of the real world's objects.

Inside an application or representative concept, three types of knowledge units may be recognized:

- declarative (standards, classification, etc.);

- procedural (solution, formulas, logical strings, causal strings, relations, etc.);

- inspirative (creative products, new approaches, new phenomenon invention, etc.).

- within the knowledge unit life cycle, the following items are classified:

- creation, finding, synthesis recognition;

- interception, representation, encoding;

- storage, system labels;

- accessing, decoding, protection, distribution;

- system relations identification, application, implementation into decision process, new design;

- implementation, new syntheses, revision, diffusion, knowledge unit consolidation synthesis, life cycle continuance.

The process executed on the system with $\mathrm{O}_{i}$ objects is symbolically characterized in the state space of intensive $P_{i}(t)$ and extensive $V_{e}(t)$ quantities:

$$
\mathrm{O}_{\mathrm{i}} \sim \mathrm{F}[\mathrm{P}(\mathrm{t}), \mathrm{V}(\mathrm{t})]
$$

Information process images - process information systems may be characterized by graphs assigned to relationships:

$$
\mathrm{I}_{\mathrm{i}} \sim \mathrm{F}[\mathrm{P}(\mathrm{t}), \Phi(\mathrm{t})]
$$

This assignment enables structural interpretations of complex information systems, evaluation of feedback, and the quality of transmission and information processing in partial information systems where an information segment issues from a graphical description displayed in Fig. 2.

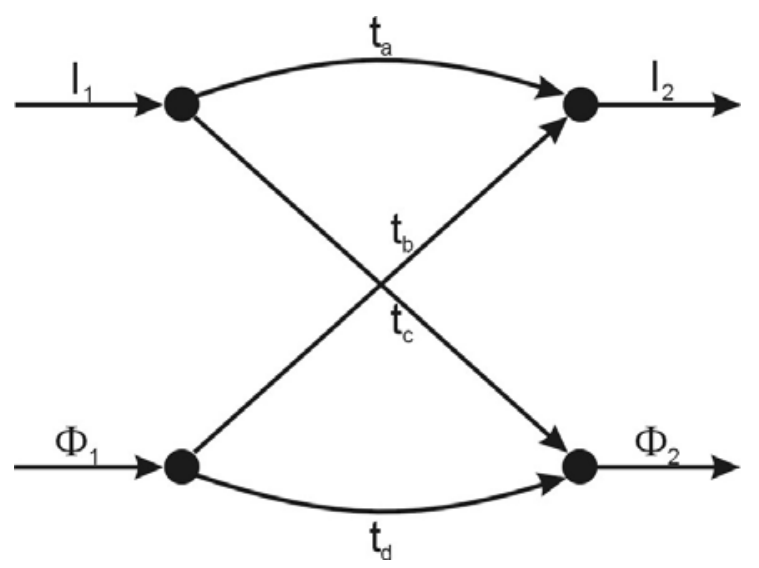

Figure 2: Information segment 
The graph issues from matrix representation in the following form:

$$
\left(\begin{array}{l}
\mathrm{I}_{2} \\
\phi_{2}
\end{array}\right) \approx \underbrace{\left(\begin{array}{ll}
\mathrm{t}_{\mathrm{a}} & \mathrm{t}_{\mathrm{b}} \\
\mathrm{t}_{\mathrm{c}} & \mathrm{t}_{\mathrm{d}}
\end{array}\right)}_{\left[\mathrm{T}_{\mathrm{i}}\right]} \cdot\left(\begin{array}{l}
\mathrm{I}_{1} \\
\phi_{1}
\end{array}\right)
$$

The matrix $T_{i}$ is called the transmission matrix of the i-th information segment, $\Phi$ i means information flow and $\mathrm{I}_{\mathrm{i}}$ information content.

\section{INFORMATION POWER}

Information performance represents a completely new quantity introduced as a tool for the evaluation of information systems effectiveness related to a probability of proper alternative selection and a probability of a proper decision in a systems control operation, see Fig. 3.,

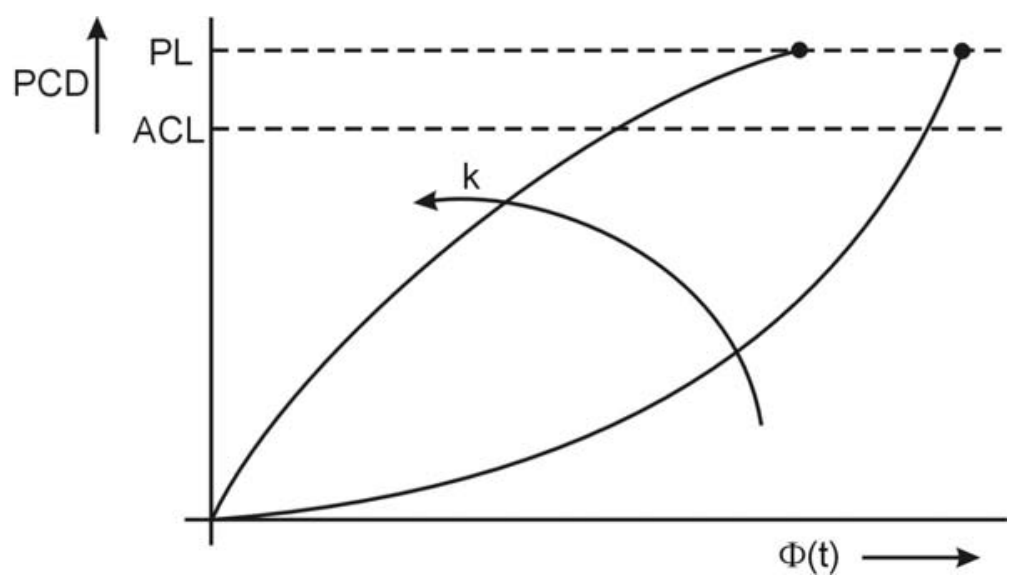

Figure 3: Probability of a proper decision in a systems control operation

where is PCD is the probability of a proper decision; PL is the possible (maximum) PCD probability level; ACL is the acceptable PCD level and $k$ is the level of knowledge in the following function:

$$
\mathrm{PCD}=\mathrm{F}[\Phi(\mathrm{t}), \mathrm{k}]
$$

where $\mathrm{F}$ is the function representing the ability of interpretation that means the control system with a higher knowledge level makes faster decisions under lesser stress.

The quantity $\mathrm{P}_{\mathrm{i}}(\mathrm{t})$ called information power is stated as the product of information content $\mathrm{I}_{\mathrm{i}}[\mathrm{t}]$ and information flow $\Phi_{\mathrm{i}}(\mathrm{t})$, and it is understood as the value of eliminated uncertainty quantity $E$ per time unit. This relationship can be stated as translated-decoded message contents $I$ in information flow $\Phi$ :

$$
P=\frac{E}{t}=I . \Phi
$$


The definition of information power may also issue from generally known formulas: power is equal to the amount of work per time unit. While applying this definition into the information power field, a crucial problem is encountered. The problem is what methodology to choose for the specification of the amount of (information) work. In simpler information systems, we can do with generally known possibilities. If we consider work as some amount of transferred information through a data network there are no problems with such process of measuring. On an active element, the amount of transferred data is measured, and we are able to simply calculate the power of this data transmission.

\section{RESONANCE EFFECT IN THE PROCESS OF CORRECT DECISION}

If we consider the magnitude and phase of the vector in the coordination of I and $\Phi$, then the knowledge parameter $k$ is acceptable as the ability of prognosis, prepared solution for the certain level of $\Phi$, which can improve the information content, probability of correct decision. The expert knowledge of the prepared solution can compensate the delay between the information content I and information flow $\Phi$.

This situation can be described with the help of (10) as:

$$
\mathrm{PCD}=\mathrm{F}\left[\Phi\left(\mathrm{t}-\varphi_{\mathrm{N} 1}\right) \cdot \hat{\mathrm{k}}\left(\mathrm{t}-\varphi_{\mathrm{N} 2}\right)\right]
$$

where phase $\varphi_{N 1}$ represents the delay in information flow and the phase $\varphi_{N 2}$ the delay in level of knowledge (both in time interval $t$ ). The synchronization condition means to find the sum of phase parameters $\left(\varphi_{N 1}+\varphi_{N 2}\right)$ :

$$
\mathrm{PCD}=\mathrm{F}\left[\Phi(\mathrm{t}) \cdot \hat{\mathrm{k}}\left(\mathrm{t}-\varphi_{\mathrm{N} 1}-\varphi_{\mathrm{N} 2}\right)\right]
$$

and compensate this phase delay by knowledge prediction. It is evident that the knowledge vector and vector of information flow must have a corresponding angle. For opposite angles we can find and express the decision-making resonance effect. In this case, the information flow is interpreted and used in the opposite way. The detailed theory of complex wave probabilistic functions is presented in (Svítek $2008 \mathrm{a}, \mathrm{b}$ ).

\section{SETTING OF FORMATS FOR KNOWLEDGE MANAGEMENT}

Data arrangement in a network is very complex as such and, therefore, it is necessary to avoid the use of incorrect data and uncertified premises. For this reason, it is necessary to build a knowledge management system. This system must be designed as a model over objects and object fields. A common knowledge management system can be described with the help of the following formula:

$$
\mathrm{S}=\mathrm{F}\left[\mathrm{E}(\mathrm{f}), \mathrm{C}(\mathrm{r}), \mathrm{P}(\mathrm{e}), \gamma\left(\mathrm{P}_{\mathrm{s}}\right)\right]
$$

where $E(f)$ is set of knowledge elements of a certain function (significance); $\mathrm{C}(\mathrm{r})$ is the relation among elements initialized by communication; $\mathrm{P}(\mathrm{e})$ is the set of processes 
running in a knowledge system (each process consists of certain running events considered as changes in knowledge state space); and $\gamma\left(\mathrm{P}_{\mathrm{s}}\right)$ is the knowledge system's genetic code based on the history, culture, and procedural sequence inside a system.

To find some complex solution for a certain problem set, we must carry out systematic procedures in systematically arranged knowledge units inside relevant knowledge segments relating to a certain knowledge field. For this purpose, a so-called knowledge map represents an appropriate tool. This knowledge map represents a knowledge relations graph in knowledge units volumes arranged in the knowledge segments. The graphical representation of the knowledge map is indicated in Fig. 4.

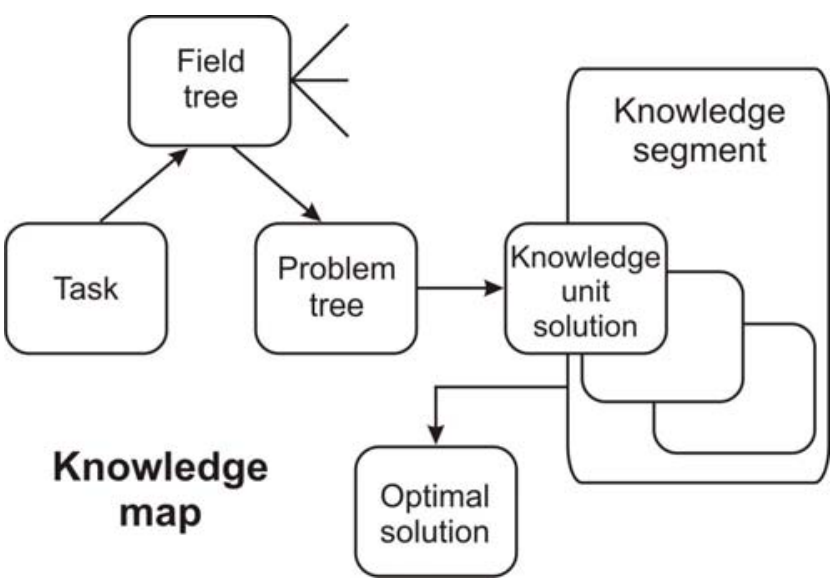

Figure 4: Knowledge map arrangement

Retrieval of the optimum solution from the solution set applying relevant data for input information represents the task. The effectiveness of knowledge management systems particularly depends on the ontology built. In this context, ontology represents a definite accordance in the sense of a shared concept and system in the knowledge set.

There are five ontology types:

- domain oriented;

- task oriented;

- generically oriented;

- application oriented;

- representation oriented.

For a more detailed solute on of certain problems, application oriented ontology may be recommended while, for archiving knowledge units needed for complex teams and project representation, representation oriented ontology is the right choice. It means that it is necessary to achieve accordance within the scope of partial teams and define mandatory document formats, primarily title descriptions as, for example, an object, problem solution, author, etc.

An ideal situation occurs as soon as the respective goals consist of:

- header + knowledge segment (knowledge units set) + context conclusions

(for application oriented ontology)

- header + authors and teams + knowledge unit 
(for representatively oriented ontology)

In object oriented knowledge management, keywords describing objects are generally used as headers. Documents as, for example, goals descriptions, systematically use HTML labels for reference to sources and quotations.

\section{OBJECT ORIENTED “KNOWLEDGE CUBE“}

Complex representation of a knowledge unit is based on the three-dimensional interpretation:

$$
\mathrm{K}_{\mathrm{ij}} \rightarrow\left(\mathrm{L}_{\mathrm{ij}}, \mathrm{N}_{\mathrm{ij}}, \mathrm{C}_{\mathrm{ij}}\right)
$$

for the application oriented knowledge element, where:

$\mathrm{Lij}=(\mathrm{Oi}, \mathrm{Pj})$ is the identification of $\mathrm{i}$-th object and $\mathrm{j}$-th process

$\mathrm{N}_{\mathrm{ij}}=\left(\mathrm{A}_{\mathrm{ij}}, \mathrm{D}_{\mathrm{ij}}\right)$ is knowledge element core part (analytical/projection);

$\mathrm{C}_{\mathrm{ij}}=\left(\mathrm{SI}_{\mathrm{ij}}, \mathrm{SE}_{\mathrm{ij}}\right)$ is core relation - sensitivity (internal/external).

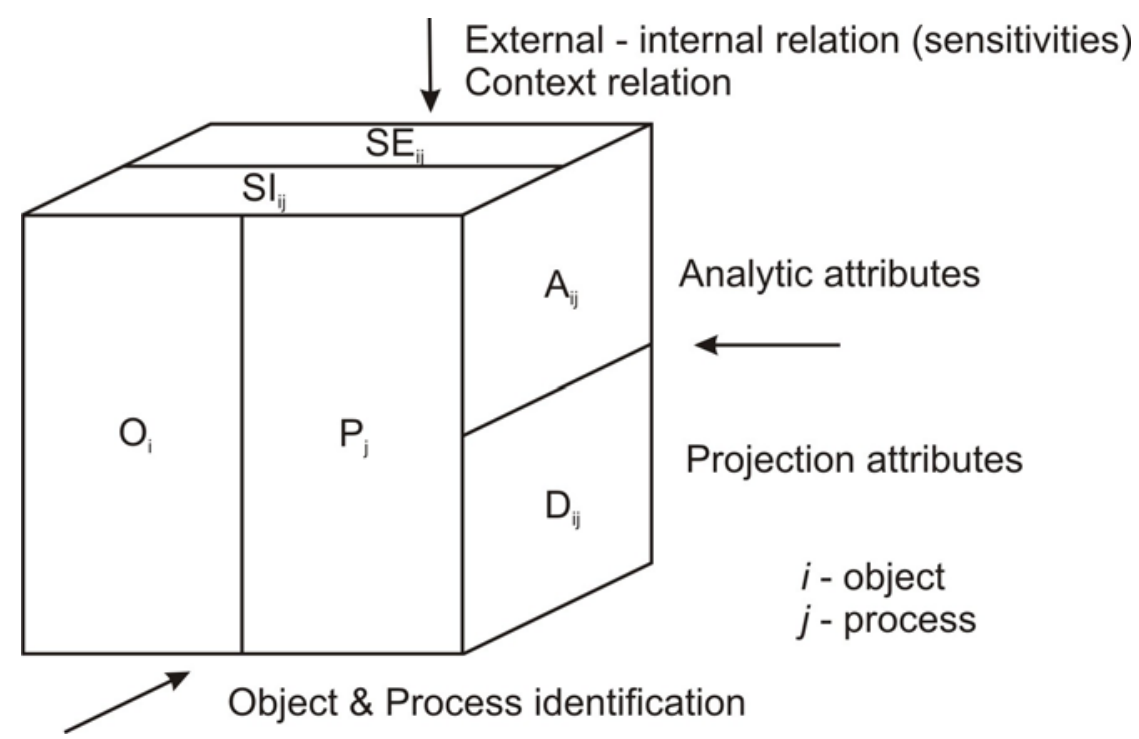

Figure 5: Object oriented "knowledge cube"

In this context, it is very important to point out the fact that a significant knowledge growth can be achieved by means of knowledge synergy among different filed trees 
and knowledge segments integrated into a meta-knowledge system based on the contextual principle (see Fig. 6).

\section{CONCLUSION}

This paper could be seen as the basic methodological approach to ITS systems terminology and effectiveness evaluation because every ITS designer tries to build a system that uses the maximum available information. We have shown that information power is the basic measure of used information in decision-making process and we have defined the conditions that must be fulfilled - information flow and information content must have the same phase in the complex domain. Every phase difference yields a worse application of available information. A critical situation can arise if phases are in the opposite direction - this situation can yield into resonance and all energy is spent on idle power.

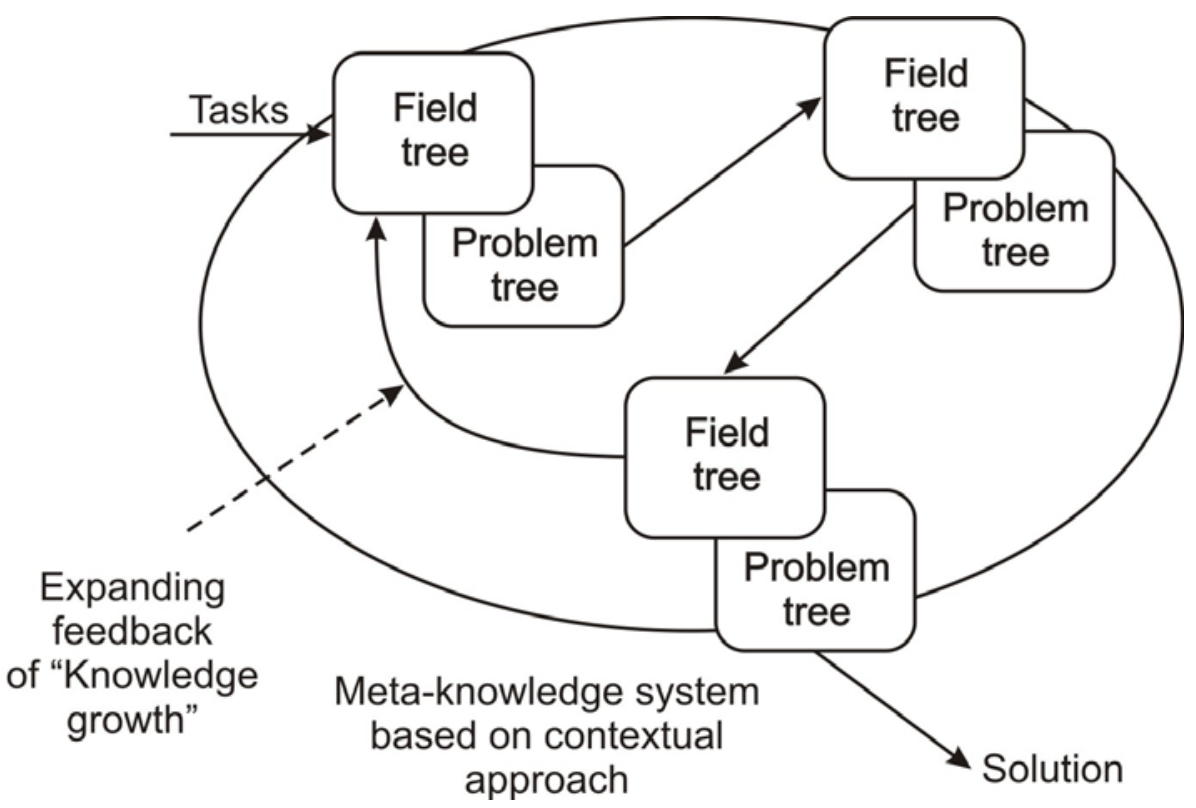

Figure 6: Exchange of corporative knowledge - sharing of best experience

\section{ACKNOWLEDGEMENT:}

The presented results were supported by Grant - IAA 201240701 - Dynamika systémových aliancí. 


\section{REFERENCES}

Moos, P., Malinovský, V., 2008: Information systems and Technologies, text book, CTU, Prague, (In Czech).

Vlček, J., 2002: Informační výkon text book CTU in Prague, (in Czech).

Vlček, J., 2003: Znalostní inženýrství Edice monografií NNW, Praha 2003; ISBN 80- 903298-0-2, (in Czech).

Svítek M., 2006: Dynamical Systems with Reduced Dimensionality, Monography NNW No.6, Czech Academy of Science, 161 pp., 2006, ISBN 80-903298-6-1.

Svítek M., 2007: Complementary variables and its application in statistics, Neural Network World 3/ 2007, Prague, pp. 237 - 253.

Svítek M., 2007: Wave probabilistic models, Neural Network World 5/2007, pp. 469 - 481, 2007.

Svítek M., 2008: Quantum System Modeling, International Journal on General Systems, Vol. 37, No.5, pp. 603 - 626.

Svítek, M., 2008: Wave probabilities and quantum entanglement, Neural Network World 5/2008, pp. 401 - 406. 